\title{
Level of physical activity and eating behavior: Risk factors associated with sedentariness among employees of a company in the city of Kinshasa province
}

\author{
Mabele Godefroid Kusuayi, Ekisawa Constant Kiama
}

Department of Kinesiology, Department of Physical Medicine and Rehabilitation, Faculty of Medicine, University of Kinshasa.

\begin{abstract}
The objective is to determine the level of physical activity, eating behavior and risk factors associated with sedentariness among employees of the Multimodal Freight Management Office of Kinshasa (OGEFREM, acronym). Cross-sectional study of the 210 employees, of which 119 (56.7\%) men and 91 (43.3\%) women, aged 18 to 59 years were randomly selected. The level of physical activity was measured by the International Physical Activity Questionnaire (IPAQ) and the eating behavior by ThreeFactor Eating Questionnaire (TFEQ-R 18). The Student's T test and Chi-square test were used to compare the variables according to level of physical activity and socioprofessional status. Logistic regression was used to identify independent determinants of physical inactivity and sedentary behavior. Of the 210 questionnaires collected, $56.7 \%$ of men and $43.3 \%$ of women show that $59.5 \%$ of the study population has a low level of physical activity and $58.5 \%$ a cognitive restriction. The average values of the following parameters: Weight, BMI, Waist circumference, systolic blood pressure, diastolic blood pressure, mean arterial pressure, pulsed pressure, blood glucose, total cholesterol, triglyceride, total body fat , visceral fat and lean mass are respectively $85 \pm 9.7 \mathrm{~kg}$, 32.6 $\pm 2.9 \mathrm{~kg} / \mathrm{m}^{2}, 99 \pm 13.0 \mathrm{~cm}, 135.6 \pm 17.0 \mathrm{mmHg}, 92.1 \pm 14.5$ $\mathrm{mmHg}, 106.6 \pm 14.3 \mathrm{mmHg}, 43.5 \pm 12.0 \mathrm{mmHg}, 129 \pm 23.9$ $\mathrm{mg} / \mathrm{dl}, 228 \pm 18.7 \mathrm{mg} / \mathrm{dl}, 169 \pm 19.5 \mathrm{mg} / \mathrm{dl}, 39.7 \pm 10.8 \%$, $8 \pm 8.9 \%$ and $28.9 \pm 9.4 \%$. The probability of having a low level of physical activity and sedentary behavior was 5 times higher among employees spending more than three hours of time sitting on the computer (OR aj $=5.18895 \% \mathrm{CI}$ (1.389-7.318), $\mathrm{p}=0.006), 3$ times higher among employees over three hours of time sitting in front of the television (OR aj = 3.042 95\% CI (1.155-8.012), p = 0.02), 3 times higher among employees who spent more than three hours of reading time (OR aj $=3.456$ 95\% CI (1.294-5.677), $\mathrm{p}=0.006$ and with cognitive dietary restriction (OR aj $=3.18895 \% \mathrm{CI}$ (1.389-7.318), $\mathrm{p}=0.006)$, cognitive dietary restriction $(\mathrm{OR}=$
\end{abstract}

3.188 95\% CI (1.389-7.318), $\mathrm{p}=0.006)$ and also 3 times higher among employees with high socio-occupational status (OR aj $=3.57$ 95\% CI (1.77-6.68), p <0.015). The employees of the Multimodal Freight Management Office of Kinshasa have a low level of physical activity and a cognitive food restriction. Time spent more than three hours of time on the computer increases the risk of becoming inactive and sedentary 5 times. On the other hand, the time spent more than three hours watching television and cognitive restriction as well as the high socio-professional status increases it three times and is positively associated with morphological, physiological, lipid profiles and body composition. In contrast, they are associated with a decrease in muscle mass and high density lipoprotein.

Keywords. Cognitive restriction, food behavior, physical activities, uncontrolled diet.

\section{Introduction}

$\mathrm{P}$ hysical activity (PA) is defined by the World Health Organization (WHO) and the Physical Activity Guidelines Advisory Committee (PAGAC) as "any body movement produced by the contraction of skeletal muscles that increases energy expenditure over the expenditure of rest. PA is a complex, multidimensional behavior. For each activity the characteristics to be taken into account are context, type, duration, frequency and intensity (OMS, 2010; Beliveau \& Leger, 2004). Worldwide, approximately 3.2 million deaths each year are attributable to lack of exercise. The decrease in PA occurs during adolescence and continues throughout one's life. It is linked to sedentary work, motorized 
modes of transport or passive leisure activities (television, video games ...). Lack of exercise is considered the fourth leading risk factor for death worldwide (Bellocq \& Cabillic, 2009). One of the main risk factors for non-communicable diseases (NCDs) is unhealthy dietary behavior, along with excess energy intake. Caloric restriction through employee-provided diets eating disorders and malnutrition (Rossner, 1992). These eating disorders are often underestimated in their severity and their impact on therapeutic possibilities (Godefroid et al., 2018). Repeated failures often lead to loss of confidence, low self-esteem, depression, and increased disease (Brownell, 1995). The framework allows to influence the behavior of a large number of employees with respect to health. People must have the opportunity to make healthy choices in their workplace to be less at risk. In addition, the cost to the employer of the morbidity attributed to noncommunicable diseases is increasing rapidly. The workplace should be used to make healthy eating choices and encourage exercise (Doucet, 2004; Abrams et al., 1994). The change in lifestyle, with the increasingly sedentary nature of professional activities, the motorization of means of transport and household chores, has been accompanied by a decrease in physical expenditure of the population. However, the practice of a regular PA adapted in terms of frequency, duration, intensity and nature as well as the limitation of sedentarily, constitute with a healthy eating behavior, major factors of acquisition and maintaining a good state of health. PA is involved, as well as eating habits and behavior, in the prevention of a large number of chronic diseases (cardiovascular diseases, diabetes, obesity, cancers) (Prévention des Maladies Chroniques, 2005). Despite the scientific interest in combating physical inactivity, sedentary lifestyle and poor nutritional behavior, as well as their predisposition to chronic no communicable diseases, no study has been conducted in the African workplace, particularly in the Republic of Korea. Democratic Republic of Congo. The purpose of this paper is to determine the level of physical activity (LPA), eating behavior and risk factors associated with sedentariness among employees of the Multimodal Freight Management Office in Kinshasa, Democratic Republic of Congo.

\section{Methods}

It is a descriptive and analytical cross-sectional study, which took place from 27 November 2013 to
27 January 2014, in 13 directorates of the so-called firm, Multimodal Freight Management Office of the city of Kinshasa, capital of the Republic of Congo. This industry specializes in the multimodal transport sector. Staff do most of their work from 7:30 am to 3:00 pm while sitting on the computer.

\section{Population and Sampling}

The company's employees, regardless of their rank (command or collaboration executives and enforcement agents) were recruited on a voluntary basis by performing a simple random draw. The population known to us was 400 employees of both sexes. The calculation of the minimum sample size was based on Robert and Daryle's formula (Gamila \& Dallongeville, 2003). Simple random sampling was used to build the workforce of 210 employees in our survey from the company's staff list. The inclusion criterion included being aged 18 and over and in good health, born of two Congolese parents and employed at the Multimodal Freight Office for at least one year of service. All selected participants provided informed consent prior to participating in the study.

\section{Selection Criteria}

Included in this study was any agent of the Multimodal Freight Management Board (OGEFREM acronym) who voluntarily and freely gave his informed consent to participate in the study.

\section{Data Collection}

Data collected included socio-demographic characteristics (age and sex), occupational status (command frameworks, collaborative settings and enforcement agents), eating behaviors (cognitive restriction, uncontrolled diet and emotional eating) and sedentary behaviors (setting more than three hours watching television, working on the computer and reading). The following anthropometric parameters: height in $\mathrm{cm}$ was measured using the Seca brand portable toe, while waist circumference (TT) in $\mathrm{cm}$ and hip circumference (TH) in $\mathrm{cm}$ by a metric tape. The morbid-mortal risks by the ratio Abdo-hip (RAH) in $\mathrm{cm}$, the weight in $\mathrm{Kg}$ and the body composition (the total body fat, muscular mass and intra-abdominal fat) by OMRON Brand Balance Inpedancemeter BF-511 Health care Netherlands / the Netherlands (Manufacturer / City / Country). The $\mathrm{BMI}$ in $\mathrm{kg} / \mathrm{m} 2$ was calculated by the mass (expressed 
in kilograms) divided by the square of the height of the person (in meters). The following lipid parameters: HDL-C, LDC-C, CT and triglycerides were measured in employees fasting for at least 12 hours on serum by clinical laboratory biologists of MOKOLE Hospital Center of Mont Ngafula in Kinshasa using the method colorimetric enzymatic and Elitech group kits (Sées, France). The PA questionnaire used was the IPAQ in its short form in French (Kohl et al., 2012, Hagstromer, Oja \& Sjostrom 2006, IPAQ, 2005). There are three sections on high intensity PA, moderate intensity $\mathrm{PA}$ and low intensity PA, and four types respectively, PA, work, leisure, where employees must specify the number of days per week and the duration of each of these types of activities. It also includes a question about sedentary behavior with questions about the average time spent usually seated daily in sedentary occupations, namely television, computer or video games and reading. Information on the motivations and factors limiting the practice of PA has also been requested (Sjöström et al., 2006; Kohl et al., 2012; IPAQ Research Committee, 2005). To diagnose eating behavior, we used the questionnaire TFEQ-R 18 (Three-Factor Eating Questionnaire) with 18 questions (Ozen et al., 2011). It explores common dietary practices and evaluates three types of eating behavior (Coste, 2006): Cognitive restriction is defined as the tendency to consciously limit food intake to be in good health. It is a voluntary constraint on eating behavior. This restriction is a deliberate choice whose purpose is weight control. The modalities of inhibition of food intake are variable (skipped meals, low calorie diets, fasting), as well as possible health control behaviors (Ginsberg \& Stalenhoef, 2003). Uncontrolled feeding includes food compulsion and bulimic access. Food compulsion is characterized by the impulsive, sudden consumption of a given food, apart from a meal. In its most common form, the simple compulsion is triggered by a desire to eat and not by a feeling of hunger, and turns towards a food or a group of foods that are appreciated and characteristic for the same subject. Bulimic access is defined by episodes in which the subject, usually alone, consumes, without hunger and with gluttony of important foods. This ingestion takes place beyond any satiety, with no other limit than the gastric capacity of the subject (Ginsberg \& Stalenhoef, 2003). Emotional eating is the ability to eat too much in relation to a negative or positive feeling when the individual feels anxious, depressed alone or happy (Ginsberg \& Stalenhoef, 2003). PA was measured after 5 minutes of relaxation in position sitting on the left arm carried at the level of the heart using a mercury sphygmomanometer; three consecutive doses in one minute interval were performed and their mean defined the PA of the patient. PAS and PAD corresponded respectively to Korotkoff sounds I and V. Poor body composition was defined as total body fat ${ }^{3} 20 \%$ in men and ${ }^{3} 32 \%$ in women, intraabdominal fat (visceral) $>9 \%$ in men and women and lean mass (Muscular) $\leq 33.3 \%$ for men and ${ }^{3}$ to $24.4 \%$ for women (Browning et al., 2010). The metabolic syndrome was defined according to the US National Cholesterol Education Program (NCEP-ATPIII, 2001), by the presence of 3 or more of the following risk factors: waist circumference $\geq 94 \mathrm{~cm}$ in men and $80 \mathrm{~cm}$ in women; Arterial pressure $\geq 130 / 85 \mathrm{mmHg}$; Triglycerides $\geq 150 \mathrm{mg} / \mathrm{dl}$; HDL cholesterol $<40 \mathrm{mg}$ / dl in men, $<50 \mathrm{mg} / \mathrm{dl}$ in women; Fasting blood glucose $\geq 110 \mathrm{~g} / 1$ (Godefroid et al., 2018).

\section{Statistical Analyzes}

The study data was encoded on Excel 2010 and analyzed on the SPSS 21.0 software. The data are expressed as mean \pm standard deviation (SD) for normally distributed and median continuous variables (Interquartile Space, EIQ) for non-normally distributed variables. The qualitative variables are expressed as absolute frequency (relative frequency in percent). Student's t-test was used to compare the averages of 2 groups; the Mann Whitney $U$ test was used to compare the medians of 2 groups. The comparison of proportions was made using the $\mathrm{Chi}$ square test. Independent determinants of physical inactivity and sedentary lifestyles were identified using logistic regression, $p<0.05$ defining the statistical significance threshold.

The protocol of the study was submitted and approved by the Ethics Committee of the Ministry of Public Health of the Democratic Republic of Congo. Respect for the Helsinki principles for research on humans has been respected and the free and informed consent of the participants has been obtained.

\section{Results}

The overall frequency of PA level of employees of the Multimodal Freight Management Office is shown in Figure 1.

Figure 1 shows that the majority of the study population has a low level of physical activity 
(59.5\%). Intense PA is found in $15.7 \%$ of employees while it is moderate in $24.8 \%$. The overall incidence of food behaviors for employees of the Multimodal Freight Management Office is shown in Figure 2.

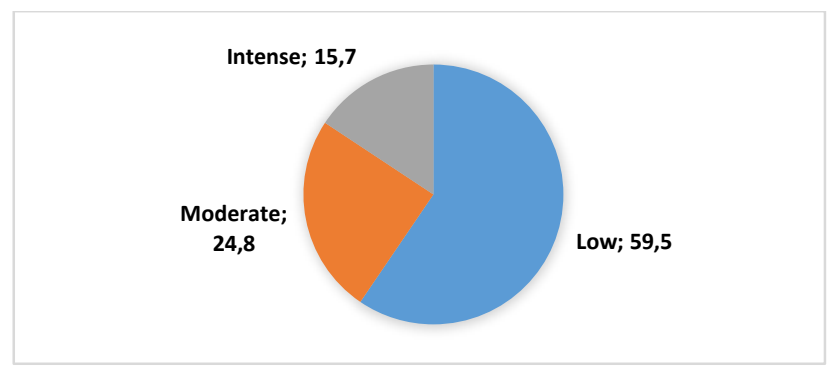

Figure 1. Distribution of study population by level of PA.

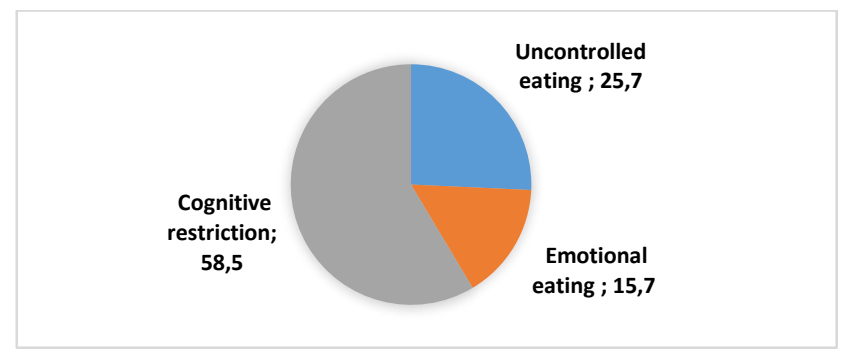

Figure 2. Distribution of the study population according to eating behavior.

Figure 2 shows that cognitive restriction is found in $58.5 \%$ of employees, $25.7 \%$ uncontrolled eating and $15.7 \%$ in emotional eating. Socio-demographic characteristics by socio-occupational status of employees are presented in Table 1.

The mean age of employees was $45.1 \pm 8.9$ years. The age of over 40 years predominated with $78.6 \%$.
The male sex was more represented with a frequency of $56.7 \%$ and a sex ratio $\mathrm{H} / \mathrm{F}$ of Comparatively between different socio-professional categories, we noted a significant difference between the level of physical activity $(p=0.002)$, age $(p=0.012)$ and sex $(p$ $=0.003$ ). Depending on the type of PA, motivations, limiting factors, and employee eating behaviors are shown in Table 2.

The type of PA that was frequently found among employees was work (47.6\%) and leisure with command executives predominating (24.3\%). The dietary behavior observed in command cadres was more cognitive restriction (31.4\%) and uncontrolled diet $(16.7 \%)$ while emotional eating accounted for $11.4 \%$. This socio-professional category remains, compared to the other two, more than three hours sitting on the computer $(40.4 \%)$ and watching television $(13.3 \%)$. The frequencies of physical activity level and mean plus or minus standard deviation of clinical parameters as a function of nutritional status are presented in Table 3.

The level of low PA was significantly higher in obese $(46.1 \%$ vs. $2.8 \%$ than in normal-weight, $\mathrm{p}=$ $0.0001)$. The frequency of overweight and obesity was significantly higher high if total body fat, visceral fat were very high $(p=0.0001)$. Decreased lean or muscle mass ( $p=0.0001)$ increased the rate of overweight and obesity. If the agent became more and more inactive, the rate of overweight and obesity increased significantly with the level of PA. The cardiovascular risk factors related to the metabolic syndrome as a function of the level of PA are presented in Table 4.

Table 1

Socio-demographic characteristics by socio-professional status (f (\%); Mean \pm SD).

\begin{tabular}{llccccc}
\hline \multicolumn{2}{l}{ Variables } & $\begin{array}{c}\text { Entire group } \\
\mathrm{n}=210)\end{array}$ & $\begin{array}{c}\text { Commanders } \\
(\mathrm{n}=125)\end{array}$ & $\begin{array}{c}\text { Frames collaborators } \\
(\mathrm{n}=52)\end{array}$ & $\begin{array}{c}\text { Executives } \\
(\mathrm{n}=33)\end{array}$ & $\mathrm{p}$ \\
\hline LPA & & & & & & \\
& Low & $125(59.5 \%)$ & $71(33.8 \%)$ & $24(11.4 \%)$ & $15(7.1 \%)$ & \\
& Moderate & $52(24.8 \%)$ & $33(15.7 \%)$ & $21(10 \%)$ & $5(2.3 \%)$ & 0.002 \\
& Intense & $33(15.7 \%)$ & $21(10 \%)$ & $7(3.3 \%)$ & $13(6.2 \%)$ & \\
Age & & $45.1 \pm 8,9$ & $46.9 \pm 9.4$ & $44.8 \pm 8.2$ & $43.6 \pm 13.6$ & \\
& $<40$ years old & $45(21.4 \%)$ & $28(13.3 \%)$ & $8(3.8 \%)$ & $9(9 \%)$ & 0.012 \\
& $\geq 40$ years & $165(78.6 \%)$ & $97(46.2 \%)$ & $44(21 \%)$ & $24(11.4 \%)$ & \\
Sex & & & & & & \\
& Male & $119(56.7 \%)$ & $76(36.2 \%)$ & $29(13.8 \%)$ & $14(6.7 \%)$ & 0.003 \\
& Female & $91(43.3 \%)$ & $49(23.3 \%)$ & $23(11 \%)$ & $19(9 \%)$ & \\
\hline
\end{tabular}


Table 2

Type of physical activity, limiting factors of physical activities (PA), eating and sedentary behavior according to socio-professional status ( $\mathrm{f}(\%)$.

\begin{tabular}{|c|c|c|c|c|c|}
\hline Variables & $\begin{array}{l}\text { Entire group } \\
\quad(\mathrm{n}=210)\end{array}$ & $\begin{array}{l}\text { Commanders } \\
\qquad(\mathrm{n}=125)\end{array}$ & $\begin{array}{l}\text { Frames Collaborators } \\
\qquad(\mathrm{n}=52)\end{array}$ & $\begin{array}{l}\text { Executives } \\
\quad(\mathrm{n}=33)\end{array}$ & $\mathrm{p}$ \\
\hline TPA Low of & $100(47.6)$ & $51(24.3)$ & $32(15.2)$ & $17(8.1)$ & 0.004 \\
\hline Work & $49(23.3)$ & $34(16.2)$ & $9(4.3)$ & $6(2.8)$ & \\
\hline Leisure & $61(29)$ & $40(19)$ & $11(5.2)$ & $10(4.7)$ & \\
\hline Shifting & $47(22.3)$ & $35(16.7)$ & $7(3.3)$ & $5(2.3)$ & \\
\hline Powered & $14(6.6)$ & $5(2.3)$ & $4(1.9)$ & $5(2.3)$ & \\
\hline \multicolumn{6}{|l|}{ Factors Limited } \\
\hline Problem of Lack Time & $118(56.1)$ & $54(25.7)$ & $53(25.2)$ & $11(5.2)$ & 0.006 \\
\hline Not Want & $9(4.3)$ & $2(1)$ & $4(1.9)$ & $3(1.4)$ & \\
\hline Health Problem & 33 (15.7) & $16(7.6)$ & $9(4.3)$ & $8(3.8)$ & \\
\hline Work Problem & $50(23.8)$ & $20(9.5)$ & $13(6.2)$ & $17(8.1)$ & \\
\hline \multicolumn{6}{|l|}{ Comportment Eating } \\
\hline Cognitive Restriction & $123(58.5)$ & $66(31.4)$ & $39(18.6)$ & $18(8.5)$ & 0.001 \\
\hline Uncontrolled & $54(25.7)$ & $35(16.7)$ & $10(4.8)$ & $9(4.2)$ & \\
\hline Emotional & $33(15.7)$ & $24(11.4)$ & $3(1.4)$ & $6(2.8)$ & \\
\hline \multicolumn{6}{|l|}{ Sedentariness } \\
\hline Time Spent Watching TV & $52(24.7)$ & $28(13.3)$ & $14(6.6)$ & $10(4.7)$ & 0.0001 \\
\hline Time Spent on the Computer & $141(67.1)$ & $85(40.4)$ & $30(14.2)$ & $26(12.3)$ & \\
\hline Time Spent Reading & $17(8)$ & $7(3.3)$ & $8(3.8)$ & $2(0.9)$ & \\
\hline
\end{tabular}

TPA: Type of Physical Activity

Table 3

Frequencies of physical activity level and mean clinical parameters by nutritional status.

\begin{tabular}{lcccc}
\hline Variables & $\begin{array}{c}\text { Normal-weight } \\
\mathrm{n}=33\end{array}$ & $\begin{array}{c}\text { Overweight } \\
\mathrm{n}=50\end{array}$ & $\begin{array}{c}\text { Obesity } \\
\mathrm{n}=101\end{array}$ & $\mathrm{p}$ \\
\hline LPA Low, $\mathrm{n}(\%)$ & $6(2.8)$ & $48(22.8)$ & $97(46.1)$ & 0.0001 \\
LPA Moderate, $\mathrm{n}(\%)$ & $11(5.2)$ & $1(0.4)$ & $3(1.4)$ & 0.041 \\
LPA Intense, $\mathrm{n}(\%)$ & $16(7.6)$ & $1(0.4)$ & $1(0.4)$ & 0.0356 \\
Weight $(\mathrm{Kg})$ & $62 \pm 8.8$ & $75 \pm 8.4$ & $84 \pm 12.0$ & 0.036 \\
Height $(\mathrm{m})$ & $1.62 \pm 0.07$ & $1.63 \pm 0.07$ & $1.64 \pm 0.10$ & 0.389 \\
BMI $\left(\mathrm{kg} / \mathrm{m}^{2}\right)$ & $23.8 \pm 2.9$ & $28.8 \pm 2.8$ & $32.3 \pm 3.5$ & 0.0001 \\
Total fat $(\%)$ & $38.4 \pm 10.4$ & $39.6 \pm 9.9$ & $40 \pm 12.2$ & 0.0001 \\
Visceral fat $(\%)$ & $9.6 \pm 8.3$ & $10.8 \pm 8.7$ & $11.2 \pm 9.7$ & 0.0001 \\
Lean mass $(\%)$ & $31.9 \pm 9.4$ & $21.7 \pm 9.4$ & $20 \pm 6.7$ & 0.0001 \\
\hline
\end{tabular}

LPA: Level of physical activity

Cardiovascular risk factors related to the metabolic syndrome were significantly higher among inactive employees $(p=0.0001)$. If the agent became more active, the cardiovascular risk factors related to the metabolic syndrome increased significantly with the level of PA $(p<0.0001)$.
In univariate analysis, the time spent on the computer, the time spent watching television, the cognitive restriction, uncontrolled diet, the female sex, the age of over 40 years and the high socioprofessional status are the determinants of physical inactivity and sedentary behavior. After adjustment, the probability of having a low level of physical 
activity and sedentary behavior was 5 times higher among employees spending more than three hours of time sitting on the computer $(\mathrm{OR}$ aj $=5.18895 \% \mathrm{CI}$ (1.389-7.318) ), $\mathrm{p}=0.006), 3$ times higher among those sitting in front of the television (OR aj $=3.04295 \% \mathrm{CI}$ (1.155-8.012), $\mathrm{p}=0.024), 2$ times higher among employees spending more than three hours of sitting time to read (OR aj $=3.45695 \% \mathrm{CI}(1.294-5.677), \mathrm{p}=$ 0.006 and cognitive restriction $(\mathrm{OR}$ aj $=3.18895 \% \mathrm{CI}$ (1.389-7.318), $\mathrm{p}=0.006$ ) as well as 3-fold higher in those with a high socio-professional status $(\mathrm{OR}$ aj $=$ 3.57 95\% CI, 1.77-6.68), $\mathrm{p}<0.015)$.

Table 4

Cardiovascular risk factors related to metabolic syndrome by level of PA.

\begin{tabular}{lcccc}
\hline FRCV related to SM & Low $(\mathrm{n}=52)$ & Moderate $(\mathrm{n}=52)$ & Intense $(\mathrm{n}=33)$ & $\mathrm{p}$ \\
\hline Waist circumference $(\mathrm{cm})$ & $99 \pm 13.0$ & $79.8 \pm 10.8$ & $78.69 \pm 10.6$ & 0.0001 \\
Blood glucose $(\mathrm{mg} / \mathrm{dl})$ & $129 \pm 24.8$ & $129 \pm 27.0$ & $126 \pm 29.0$ & 0.031 \\
CT (mg/dl) & $228 \pm 18.7$ & $210 \pm 17.3$ & $208 \pm 18.5$ & 0.057 \\
HDL-C (mg/dl) & $38.6 \pm 18.5$ & $85 \pm 24.0$ & $86 \pm 22.9$ & 0.002 \\
LDL-C (mg/dl) & $170 \pm 13.9$ & $162 \pm 14.8$ & $160 \pm 14.6$ & 0.381 \\
Triglycerides (mg/dl) & $169 \pm 19.5$ & $150 \pm 19.5$ & $148 \pm 17.3$ & 0.001 \\
PAS (mmHg) & $135.6 \pm 17.0$ & $127.2 \pm 15.3$ & $102.3 \pm 20.3$ & 0.045 \\
PAD (mmHg) & $92.1 \pm 14.5$ & $82.5 \pm 11.8$ & $73.1 \pm 15.9$ & 0.028 \\
\hline
\end{tabular}

FRCV: Cardiovascular Risk Factors, SM: Metabolic Syndrome

Table 5

Determinants of physical inactivity (low physical activity level) and sedentary behavior.

\begin{tabular}{|c|c|c|c|c|c|c|}
\hline \multirow{2}{*}{ Variables } & \multicolumn{3}{|c|}{ Univariate analysis } & \multicolumn{3}{|c|}{ Multivariate analysis } \\
\hline & $\mathrm{p}$ & OR Gross & IC95\% & $\mathrm{p}$ & OR aj & IC $95 \%$ \\
\hline Sedentary behavior & \multicolumn{3}{|c|}{1} & \multicolumn{3}{|c|}{1} \\
\hline Time Spent Watching TV & 0.02 & 2.71 & 1.171 & 0.024 & 3.042 & 1.155 \\
\hline Time Spent on the Computer & 0.003 & 5.064 & 1.477 & 0.006 & 5.188 & 1.389 \\
\hline Time Spent Reading & 0.012 & 2.12 & 1.183 & 0.006 & 3.456 & 1.294 \\
\hline Total Sedentary Time & 0.039 & 0.928 & 0.865 & 0.044 & 0.422 & 0.852 \\
\hline Food Behavior & \multicolumn{3}{|c|}{1} & \multicolumn{3}{|c|}{1} \\
\hline Uncontrolled & 0.005 & 2.874 & 1.379 & 0.054 & 2.19 & 0.987 \\
\hline Emotional & 0.039 & 0.928 & 0.865 & 0.044 & 0.422 & 0.852 \\
\hline Food Restriction & 0.003 & 3.064 & 1.477 & 0.006 & 3.188 & 1.389 \\
\hline Sex & \multicolumn{3}{|c|}{1} & \multicolumn{3}{|c|}{1} \\
\hline Male & 0.008 & 0.998 & 0.996 & 0.011 & 0.697 & 0.994 \\
\hline Female & 0.000 & 4.756 & 2.029 & 0.603 & 1.334 & 0.451 \\
\hline Age & \multicolumn{3}{|c|}{1} & \multicolumn{3}{|c|}{1} \\
\hline$<40$ years old & 0.000 & 6.5 & 2.724 & 0.881 & 1.093 & 0.341 \\
\hline$\geq 40$ years & 0.000 & 9.926 & 3.987 & 0.514 & 1.599 & 0.39 \\
\hline Socioprofessional status & \multicolumn{3}{|c|}{1} & \multicolumn{3}{|c|}{1} \\
\hline Commanders & 0.034 & 5.05 & 1.13 & 0.015 & 3.57 & 1.77 \\
\hline Collaboration frameworks & 0.041 & 2.288 & 1.035 & 0.163 & 1.89 & 0.773 \\
\hline Executing agents & 0.017 & 0.962 & 0.931 & 0.433 & 0.986 & 0.951 \\
\hline
\end{tabular}




\section{Discussion}

This study was conducted to determine the level of physical activity and eating behavior of employees of the Multimodal Freight Management Office in Kinshasa, capital of the Democratic Republic of Congo. The prevalence of low physical activity level (physical inactivity) among employees was 59.5\%. It is higher than that (10 to $46 \%$ ) of the study The International Prevalence Study on PA: results from 20 countries, carried out from 2002 to 2004 on a population aged 18 to 65 years and used, like us, the same questionnaire IPAQ (Bauman et al., 2009).The prevalence of eating disorders expressed by cognitive restriction was $58.5 \%$ followed by $25.7 \%$ for uncontrolled feeding. This result is close to those of Kusuayi et al. (2018). The level of low physical activity or physical inactivity was predominantly among commanders $(33.8 \%)$ over 40 years $(46.2 \%)$ males $(36.2 \%)$, and decreased with age, sex and sociopressure status. This result is consistent with those of Muller et al. (2003) as well as that of Kantomaa et al. (2007) who observed that, the more one occupies the functions of command and one As age increases, the level of physical activity decreases and sedentary behavior increases (Muller, 2003; Kantomaa et al., 2007).

In the study of Lafay et al. (2009), $48.4 \%$ of men and $41.3 \%$ of women were inactive. This physical inactivity was in the order of $63.9 \%$ for men and $29.5 \%$ for women in the ENNS national health nutrition study (2006-2007) (Lafay et al., 2009; Salanave et al., 2015; USEN, 2007).The majority of responses $(47.6 \%)$ of employees to the question of type of low physical activity are those related first to work, then to displacement (29\%). They are more oriented towards sedentary or motorized movement than active (22.3\% against $6.6 \%)$. Our results are similar to those obtained by the survey, barometer health nutrition 2010 which is $57.7 \%$ (Baromètre Santé Nutrition, 2010).The first reason for the physical inactivity advanced by employees is related to lack of time. The higher the function, the more poor eating behavior $(p=0.001)$. In our study, cognitive restriction $(31.4 \%)$ and uncontrolled eating $(16.7 \%)$ were identified more frequently among commanders as they are those for whom leisure motivation is low $(6.7 \%)$. These are more likely to give the reason of health as motivation. These results correspond to those of the Baromètre santé (2000) study. Our study also showed that $40.4 \%$ of command executives spend more than three hours of time on the computer and $13.3 \%$ watch television. We also observed a positive association between sedentary behavior, eating behavior and high socioprofessional status $(p=0.0001)$. The higher the grade, the more sedentary one becomes and the eating behavior is changed. This finding is consistent with those of Beryman et al. 2008, de Burton et al. 2000 as well as those of Barnett et al. 2008 who noted that high socio-occupational status is intimately associated with physical inactivity, eating behavior and sedentary lifestyle. Finally, our investigation showed that working time beyond three hours of time on the computer, watching television, having cognitive restriction and belonging to high socioprofessional status, increased the risk of becoming inactive by 3 to 5 times / or sedentary. A positive relationship was observed between morphological, physiological, lipid profiles, body composition and sedentary behavior $(p=0.001)$ (Beunza et al., 2007; Ekelund et al., 2009). In contrast, these same profiles are associated with a decrease in muscle mass and high density lipoprotein $(p=0.002)$. This result is consistent with those of Beunza et al. 2007, from Ekelund et al. 2009, by Fung et al. 2000, Helmerhorst et al. 2009 who studied the relationship between time sitting on the computer, in front of television and the bio marker of cardiovascular risk factors. However, it is easy to emphasize as Gardiner et al. 2011, Gomez-Cabello et al. 2012, Gao et al. 2007, Gennuso et al. 2013, Stamatakis et al. 2012, that sedentary lifestyle is related to an increase in morphological profile, physiological and body composition.

\section{Conclusion}

Employees of the Multimodal Freight Management Office in Kinshasa have a low level of physical activity and a cognitive food restriction. The time they spend more than three hours on the computer increases the risk of becoming inactive and sedentary 5 times. On the other hand, this same time increases 3 times to watch television and to spend reading as well as to have the cognitive restriction. It is linked to high socio-professional status. In contrast, the parameters studied are associated with a decrease in muscle mass and high-density lipoprotein. Obesity and the metabolic syndrome are common pathologies in the workplace where physical inactivity and an unhealthy eating habit are key modifiable risk factors. Awareness-raising and the development of a structured exercise intervention program combined with low-calorie, low-salt, high 
vitamin and fiber nutrition education is urgently needed to improve health in the workplace.

\section{Acknowledgment}

We express our thanks not only to all the employees of the Multimodal Freight Management Office of Kinshasa who accepted to participate in this study but also to the members of the Management Committee of this company for their authorization. Our gratitude is addressed to the Assistants of the Department of Physical Medicine and Rehabilitation especially of the Kinesiology Department who participated in the data collection campaign.

\section{Conflict of Interest}

The authors declare that they have no conflict of interest. They are solely responsible for the writing and content of this article.

\section{References}

Abrams DB, Boutwell WB, Grizzle J, Heimendinger J, Sorensen G, Varnes J. Cancer control at the workplace: the Working Well trial. Preventive Medicine, 1994, 23(1): 15-27.

Barnett TA, Gauvin L, Craig CL, Katzmarzyk PT. Distinct trajectories of leisure time physical activity and predictors of trajectory class membership: A 22 year cohort study. Int J Behav Nutr Phys Act, 2008, 5: 57.

Baromètre santé 2000. Cfes 2000.

Baromètre santé nutrition, Activité physique et sédentarité en Languedoc-Roussillon, Observatoire Régional de Santé Languedoc-Roussillon, 2010.

Bauman A, Bull F, Chey T, Craig CL, Ainsworth BE, Sallis JF, Bowles HR, Hagstromer M, Sjostrom M, Pratt M, the IPS Group. The International Prevalence Study on Physical Activity: results from 20 countries. International Journal of Behavioral Nutrition and Physical Activity, 2009; 6:21.

Beliveau L, Leger L. L'évaluation de la condition physique où, quand, comment, pourquoi? Le Médecin du Québec, 2004; 39(4): 11.

Bellocq A, Cabillic M. L'actimètre en pratique. Société de Pneumologie de Langue Française, 2009, p. 9.

Bergman P, Grjibovski AM, Hagstromer M, Bauman A, Sjostrom $\mathrm{M}$. Adherence to physical activity recommendations and the influence of socio-demographic correlates - a population-based cross-sectional study. BMC Public Health, 2008; 8: 367.

Beunza JJ, Martinez-Gonzalez MA, Ebrahim S, Bes-Rastrollo M, Nunez J, Martinez JA, Alonso A. Sedentary behaviors and the risk of incident hypertension: the SUN Cohort. Am J Hypertens, 2007; 20: 1156-1162.
Brownell KD. Matching individuals to treatments. In: Brownell KD, Fairburn CG, (eds). Eating discorders and obesity. New-York, London: The Guilford Press, 1995: pp. 552-557.

Browning LM, Hsieh SD, Ashwell M. A systematic review of waist-to-height ratio as a screening tool for the prediction of cardiovascular disease and diabetes: 0.5 could be a suitable global boundary value. Nutr Res Rev, 2010; 23: 247-269.

Burton NW, Turrell G. Occupation, hours worked, and leisuretime physical activity. Preventive Medicine, 2000; 31(6): 673-681.

Coste M. 2006. Prévalence du syndrome métabolique chez les patients de 30-64 ans durant un mois de consultation. Thèse de Médecine. Université de Lyon, France, 2006: pp. 19.

Doucet E. L'activité Physique et la maitrise du poids, Revue Formation continue. le Médecin du Québec, 2004; 39(2).

Ekelund U, Brage S, Griffin SJ, Wareham NJ. Objectively measured moderate- and vigorous-intensity physical activity but not sedentary time predicts insulin resistance in high-risk individuals. Diabetes Care, 2009; 32: 1081-1086.

Fung TT, Hu FB, Yu J, Chu NF, Spiegelman D, Tofler GH, Willett WC, Rimm EB. Leisure-time physical activity, television watching, and plasma biomarkers of obesity and cardiovascular disease risk. Am J Epidemiol 2000; 152: $1171-1178$

Gamila S, Dallongeville J. Epidémiologie du syndrome métabolique en France. Med Nutr, 2003; 39: 89-94.

Gao X, Nelson ME, Tucker KL. Television viewing is associated with prevalence of metabolic syndrome in Hispanic elders. Diabetes Care, 2007; 30: 694-700.

Gardiner PA, Healy GN, Eakin EG, Clark BK, Dunstan DW, Shaw JE, Zimmet PZ, Owen N. Associations between television viewing time and overall sitting time with the metabolic syndrome in older men and women: the Australian Diabetes, Obesity and Lifestyle study. J Am Geriatr Soc, 2011; 59: 788-796.

Gennuso KP, Gangnon RE, Matthews CE, Thraen-Borowski KM, Colbert LH. Sedentary behavior, physical activity, and markers of health in older adults. Med Sci Sports Exerc, 2013; 45: 1493-1500.

Ginsberg HN, Stalenhoef AF. The metabolism syndrome: targeting dyslipidaemia to reduce coronary risk. J Cardiovasc Risk, 2003; 10: 121-128.

Godefroid KM, Constant NE, Christophe D, Francois LB, Alosha NN. Effect of a structured physical exercises program on cardiovascular risk factors related to the metabolic syndrome in obese workers of Kinshasa in Democratic Republic of Congo. Sports and Science, 2018; 33(3): 115122

Gomez-Cabello A, Pedrero-Chamizo R, Olivares PR, HernandezPerera R, Rodriguez-Marroyo JA, Mata E, Aznar S, Villa JG, Espino-Toron L, Gusi N, Gonzalez-Gross M, Casajus JA, Ara I, Vicente-Rodriguez G. Sitting time increases the overweight and obesity risk independently of walking time in elderly people from Spain. Maturitas, 2012; 73: 337343. 
Helmerhorst HJ, Wijndaele K, Brage S, Wareham NJ, Ekelund U. Objectively measured sedentary time may predict insulin resistance independent of moderate- and vigorous intensity physical activity. Diabetes, 2009; 58: 1776-1779.

IPAQ Research Committee. Guidelines for data processing and analysis of the international physical activity (21st December 2005), 2005.

Kantomaa MT, Tammelin TH, Nayha S, Taanila AM. Adolescents' physical activity in relation to family income and parents'education. Preventive Medicine, 2007; 44(5): 410-415.

Kohl HW, Craig CL, Lambert EV, Inoue S, Alkandari JR, Leetongin G, Kahlmeier S. The pandemic of physical inactivity: global action for public health. Lancet, 2012; 380: 294-305.

Kusuayi MG, Constant NE, Christophe D, Teddy BL, Nicias KN, Francois LB. Effects of a physical exercise program on the level of physical activity and energy expenditure of obese workers in Kinshasa in the Democratic Republic of Congo. International Journal of Kinesiology \& Sports Science, 2018; 6(2): 1-6.

Lafay L, Bénetier C, Berin M. Étude individuelle nationale des consommations alimentaires: 2006-2007 (INCA- 2), 2009, p. 227.

Muller L. La pratique sportive des jeunes dépend avant tout de leur milieu socioculturel. Insee Première, 2003, n: 932.

OMS. Recommandations mondiales sur l'activité physique pour la santé. OMS, 2010, p. 57.
Ozen KB, Sarac F, Sarac S, Uluer H, Yilmaz C. Metabolic Syndrome insulin resistance, fibrinogen, hemocysteine, leptin, and Creative protein in obese patients with obstructive sleep apnea syndrome; Ann Thorac Med, 2011; 6(3): 120-125.

Prévention des Maladies Chroniques: Un investissement vital. Genève, Organisation mondiale de la Santé, 2005.

Rossner S. Factors determining long-term outcome of obesity treatment. In: Björntorp P, Brodoff BN eds. Obesity. Philadelphia: Lippincott, 1992: 712-719.

Salanave B, Verdot C, Deschamps V, Vernay M, Hercberg S, Castetbon K. La pratique de jeux en plein air chez les enfants de 3 à 10 ans dans l'Étude nationale nutrition santé (ENNS, 2006-2007). Bull Epidémiol Hebd, 2015; (30-31): 561-570.

Sjöström M, Oja P, Hagsträmer M, Smith B, Bauman A. Healthenhancing physical activity across European Union countries: The Euro barometer study. J Publ Health, 2006; 14: 291-300.

Stamatakis E, Davis M, Stathi A, Hamer M. Associations between multiple indicators of objectively-measured and selfreported sedentary behaviour and cardiometabolic risk in older adults. Prev Med, 2012; 54: 82-87.

USEN. Unité de surveillance et d'épidémiologie nutritionnelle. Étude nationale nutrition santé (ENNS, 2006) - Situation nutritionnelle en France en 2006 selon les indicateurs $\mathrm{d}$ 'objectif et les repères du Programme national nutrition santé (PNNS). Institut de veille sanitaire, Université de Paris 13, Conservatoire national des arts et métiers, 2007, p. 74. 